\title{
Multiple Traveling Salesman Problem menggunakan Algoritma Ant Colony Optimization dengan Operasi Elitism
}

\author{
Sugiarto Cokrowibowo ${ }^{* 1}$, Ismail ${ }^{2}$, Indra ${ }^{3}$ \\ 1,2,3 Program Studi Teknik Informatika, Fakultas Teknik, Universitas Sulawesi Barat \\ E-mail: *1 sugiarto.cokrowibowo@ unsulbar.ac.id, ${ }^{2}$ ismail@ unsulbar.ac.id, ${ }^{3}$ indra@ unsulbar.ac.id
}

\begin{abstract}
Abstrak
Multiple Traveling Salesman Problem (MTSP) adalah masalah optimasi kombinatorial dan merupakan perluasan dari masalah kombinatorial Traveling Salesman Problem (TSP). Implementasi MTSP ini banyak diterapkan pada masalah transportasi dan penjadwalan. MTSP merupakan masalah komputasi dengan tingkat kompleksitas np-hard. Tulisan ini membahas tentang penyelesaian MTSP menggunakan adaptasi Algoritma Ant Colony Optimization dengan operator Elitism yang berasal dari algoritma genetika. Hasil dari kombinasi algoritma ini menghasilkan solusi yang senantiasa mengalami peningkatan nilai solusi terbaik di setiap siklus semut.
\end{abstract}

Kata Kunci-Multiple Traveling Salesman Problem, Ant Colony Optimization, Algoritma Genetika, Elitisme

\section{Abstract}

The Multiple Traveling Salesman Problem (MTSP) is a combinatorial optimization problem and extension of Traveling Salesman Problem (TSP). There are many implementation of MTSP on transportation and scheduling. MTSP is an NP-hard problem. This paper study about solving MTSP using Ant Colony Optimization and Elitisme operator from Genetic Algorithm. The result of this combination algorithm enhance the solution search performace because of the elitism operation which ensure the solution value always increase.

Keywords - Multiple Traveling Salesman Problem, Ant Colony Optimization, Genetic Algorithm, Elitism

\section{PENDAHULUAN}

Multiple Traveling Salesman (MTSP) merupakan perluasan dari Traveling Salesman Problem (TSP) klasik dengan masalah komputasi berupa pencarian biaya perjalanan minimum untuk mengunjungi verteks-verteks tepat satu kali pada sebuah graf lengkap yang semua verteksnya saling berhubungan. Jika pada TSP hanya terdapat satu salesman maka pada MTSP terdapat m salesman [1]. TSP merupakan masalah komputasi kombinatorik dengan kompleksitas NP-hard. MTSP adalah generalisasi dari TSP yang melibatkan penjadwalan $m(m>1)$ salesman untuk mengunjungi $n(n>m)$ $\mathrm{kota} /$ verteks sedemikian sehingga setiap verteks hanya dikunjungi tepat sekali saja dengan total rute yang paling pendek. Sama seperti TSP, MTSP juga merupakan masalah komputasi kombinatorik dengan kompleksitas NP-hard. Untuk menyelesaikan masalah komputasi kombinatorik dengan kompleksitas NP-hard, pendekatan heuristik merupakan pilihan yang baik. Algoritma genetika yang dipresentasikan oleh Holland di awal tahun 1970an merupakan algoritma paralel, random dan adaptif yang didasarkan pada mekanisme seleksi alam dan genetika individu yang diilhami oleh teori Darwin tentang evolusi makhluk hidup. Algoritma genetika ini terbukti efektif dan telah banyak 
digunakan dalam penyelesaian masalah TSP [2].

Tulisan ini membahas akan membahas pengembangan ant colony optimization (ACO) dengan penambahan operator elitism yang berasal dari algoritma genetika untuk mempertahankan individu terbaik. Modifikasi algoritma ACO juga dilakukan untuk menyelesaikan MTSP berupa pencarian oleh tim semut, dimana pada ACO yang terdahulu pencarian yang dilakukan oleh setiap semut dilakukan secara independen sedangkan pada tulisan ini semut-semut bekerja secara tim dan dalam satu system algoritma semut terdapat beberapa tim. Manyaknya semut pada setiap tim semut adalah sama dengan banyaknya salesman (m). Sistematika penulisan adalah sebagai berikut: deskripsi masalah akan dibahas pada bab II, kemudian desain algoritma yang diusulkan akan dibahas pada bab III, selanjutnya hasil pengujian algoritma akan dibahas pada bab IV, dan terakhir, kesimpulan penelitian kan diberikan di bab V.

\section{METODE}

\subsection{Multiple Traveling Salesman Problem}

Secara umum MTSP dapat dinyatakan sebagai berikut: diberikan sebuah himpunan dengan $n$ verteks dan $m(n>m)$ salesman dengan salah satu verteks berfungsi sebagai depot, MTSP harus menentukan rute untuk semua salesman (sebanyak m salesman), dimana semua salesman harus memulai dan mengakhiri rute di verteks depot, sedemikian sehingga semua verteks kecuali verteks depot hanya akan dikunjungi tepat satu kali kunjungan dan total biaya semua rute diminimalisir. Biaya (cost) dapat berarti jarak, waktu, ongkos dan lain-lain [2]. MTSP dapat diperluas ke dalam banyak variasi. Berdasarkan depot MTSP dapat dikelompokkan menjadi MTSP single depot, MTSP multiple depots dan MTSP open ends. Perbedaan mendasar antara MTSP open ends dengan yang lain adalah bahwa pada MTSP open ends salesman tidak harus kembali lagi ke depot di setiap akhir rute [2] [3] [4] [5]. Jika salesman pada MTSP melakukan banyak pengambilan dan pengiriman barang maka disebut MTSP pick-up and delivery (MTSPPDP). Jika pelayanan salesman dibatasi oleh waktu maka disebut MSTP with time window (MTSPTW). Selain itu juga terdapat pengkombinasian dari MTSP di atas [2] [6].

MTSP dengan sejumlah $\mathrm{m}$ salesman dan $\mathrm{n}$ verteks secara formal dapat didefinisikan sebagai: diberikan sebuah graf lengkap $G=(V, E)$, dimana V adalah himpunan verteks $V=\left\{v_{1}, v_{2}, v_{3}, \ldots, v_{n}\right\}$ dan setiap edge $\left(v_{i}, v_{j}\right) \in E, i \neq j \quad$ dihubungkan dengan sebuah bobot $\quad c_{i j} \in C$ yang merepresentasikan sebuah biaya (jarak) dari verteks $i$ ke verteks $j$. Fungsi tujuan dari MTSP adalah menentukan m deret siklus Hamiltonian atau sirkuit di G dengan total bobot minimum dan setiap verteks selain verteks depot hanya dikunjungi tepat satu kali kunjungan saja [1].

Banyak peneliti yang telah mencoba untuk menghubungkan penyelesaian MTSP ke dalam Traveling Salesman Problem (TSP) dan menggunakan algoritma-algoritma eksak untuk menemukan solusinya namun hasilnya senantiasa mengalami degenerasi [7]. Kemudian, seiring berkembangnya algoritma pencarian heuristic juga mulai diminati dan diteliti penggunaannya pada MTSP. Ryan et al [8] menggunakan algoritma tabu search pada MTSP. Thompson [9] menerapkan algoritma pencarian ketetanggaan yang diberi nama Cyclic Transfers pada MTSP. Fang Chen [10], melakukan riset pada Ant Colony Optimization dan Algoritma Genetika untuk menyelesaikan TSP. Pada penelitian ini, penulis akan memperluas fusi Algoritma Genetika Ant Colony Optimization untuk menyelesaikan MTSP.

\subsection{Algoritma Ant Colony Optimization Dengan Operasi Elitisme}

Algoritma Ant colony optimization dengan operasi elitism adalah pengkombinasian penggunaan algoritma genetika dan algoritma ant colony optimization. Menurut penelitian sebelumnya, istilah penggabungan kerangka kerja algoritma ini sering juga disandingkan dengan istilah algoritma adaptive hybrid. Perbandingan hasil algoritma hybrid menunjukkan hasil yang lebih unggul dari kedua algoritma sebelum digabungkan [10] [11]. Pada penelitian ini akan digunakan penggabungan algoritma ant colony optimization dengan penambahan operator elitism untuk mempertahankan 
solusi terbaik yang telah ditemukan. Operator elitism ini diadaptasi dari operator elitism pada algoritma genetika. Selain itu, pencarian solusi oleh semut juga dilakukan dalam beberapa tim semut dengan masing-masing tim semut memiliki misi untuk mebangun satu subsiklus yang merepresentasikan perjalanan salesman. Metode ini disebut mission oriented ant team (MOAT) [12].

\section{A. Deskripsi Algoritma}

Algoritma ant colony optimization dengan operasi elitism dideskripsikan sebagai berikut:

1. Mempersiapkan sebuah model system koloni semut. Terdapat sebanyak $n$ verteks dan sebanyak $\mathrm{m}$ salesman yang masing-masing salesman akan diwakili oleh satu semut membentuk tim semut. Setiap semut akan mencari rute terpendek dimulai dari verteks depot dan berakhir di verteks depot hingga semua verteks selain verteks depot dikunjungi tepat satu kali kunjungan. Dalam satu siklus semut terdapat sebanyak t tim semut. Masing-masing tim semut akan mebangun sebuah solusi lengkap MTSP.

2. Setiap edge akan diberikan nilai inisial konsentrasi pheromone yang sama. Semakin banyak semut yang melewati suatu edge, maka nilai konsentrasi pheromone pada edge tersebut akan semakin meningkat. Mula-mula semut akan diletakkan di verteks depot untuk selanjutnya mencari veteks-verteks tujuan menggunakan persamaan probabilitas semut dan berakhir di verteks depot.

3. T tim semut yang masing-masing mewakili satu solusi lengkap MTSP selatnjutnya akan memasuki proses evolusi genetika. Setiap tim semut akan menjadi satu individu pada populasi genetika.

4. Tim semut terbaik dalam satu siklus akan menjadi individu elitisme.

5. Siklus akan terus diulang hingga siklus ke NC_MAX.

\section{B. Flowchart}

Flowchart algoritma ant colony optimization dengan operasi elitism diperlihatkan pada gambar 1.

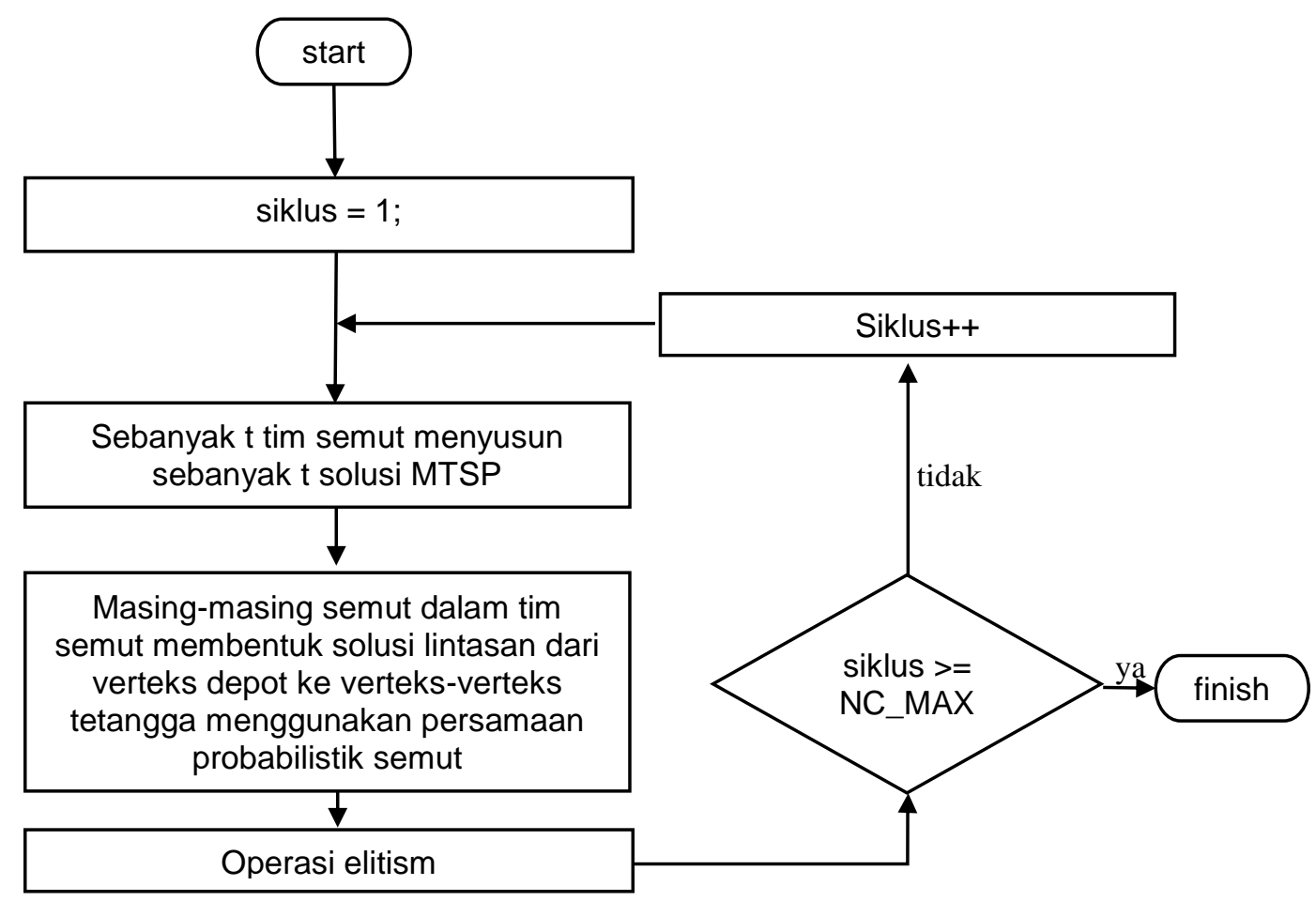

Gambar 1. Flowchart Algoritma 


\section{Diagram Class}

Diagram class untuk implementasi Algoritma ant colony optimization dengan operasi elitism diperlihatkan pada gambar 2 sebagai berikut:
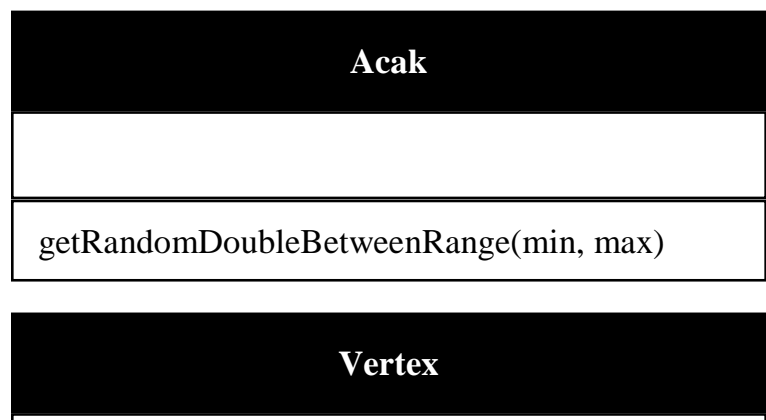

String label

Int visited

Int $x$

Int $\mathrm{y}$

getLabel( )

getVisited( )

getX( )

getY( )

setVisited(int visited)

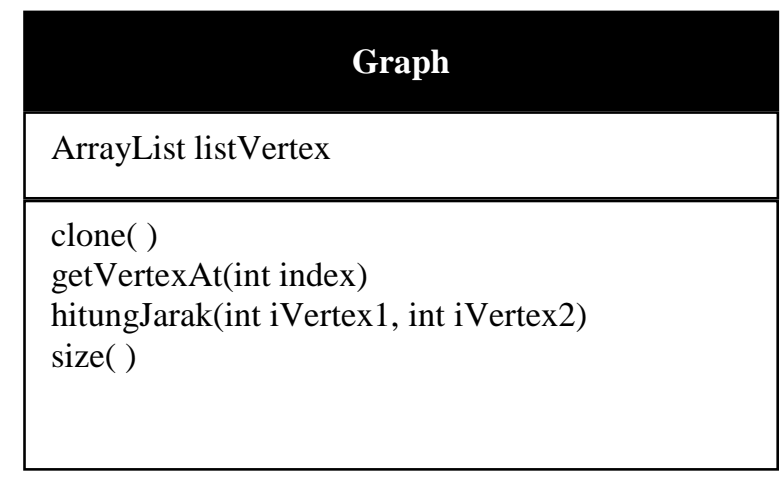

Path

\begin{tabular}{|l|}
\hline \multicolumn{1}{|c|}{ Path } \\
\hline $\begin{array}{l}\text { boolean closed } \\
\text { ArrayList iVertices }\end{array}$ \\
\hline $\begin{array}{l}\text { add( ) } \\
\text { clone( ) } \\
\text { close( () } \\
\text { getHead( ) } \\
\text { getValue( ) } \\
\text { getValueWithoutDepot( ) } \\
\text { size( ) } \\
\text { toString( ) }\end{array}$ \\
\hline
\end{tabular}

Gambar 2. Diagram Class

\section{HASIL DAN PEMBAHASAN}

Solusi Multiple Traveling Salesman Problem menggunakan Algoritma ant colony optimization dengan operasi elitism ini dikembangkan menggunakan bahasa pemrograman Java dan akan diuji pada MTSP yang dibangkitkan secara random dengan 100 verteks pada area berukuran $100 \times 100 \mathrm{px} 2$. Parameter algoritma ACO yang digunakan adalah: alpha $=1.65$, beta $=1.5$, rho $=$ $0.01, \mathrm{~m}=5,10,20,30,40$ dan 50 salesman. Akan dilakukan sebanyak 50 pengujian untuk masing masing kasus uji untuk mencari solusi optimal dan nilai rata-rata dari solusi-solusi yang diperoleh. Hasil pengujian MTSP ini diperlihatkan pada tabel 1 berikut.

Table 1. Hasil pengujian MTSP

\begin{tabular}{cccc}
\hline $\mathrm{m}$ & Value Terbaik & Test Case & Average \\
\hline 5 & 2225.781 & 7 & 2353.559 \\
10 & 2361.082 & 41 & 2556.142 \\
20 & 2788.540 & 34 & 2901.297 \\
30 & 2908.590 & 37 & 3018.092 \\
40 & 2805.831 & 20 & 2975.244 \\
50 & 2734.729 & 33 & 2897.091 \\
\hline
\end{tabular}




\section{KESIMPULAN}

Tulisan ini mengajukan pendekatan algoritma ACO dengan operasi elitism untuk menyelesaikan masalah MTSP. Pendekatan ini berupa adaptasi algoritma ACO menggunakan mission oriented ant team (MOAT) dan operasi elitism dari algoritma genetika. Untuk solusi MTSP pendekatan MOAT untuk ACO lebih realistis dibandingkan original ACO yang lebih sesuai untuk TSP dikarenakan pada MTSP terdapat lebih dari satu salesman. Pemanfaatan operator elitism juga telah meningkatkan performa algoritma dimana dengan operasi elitism ini maka solusi terbaik pada setiap siklus akan langsung disimpan dan akhirnya trend solusi akan senantiasa meningkat. Untuk pengembangan penelitian berikutnya penulis bermaksud meningkatkan penggabungan algoritma Ant Colony Optimization dan Algoritma Genetika dengan lebih banyak lagi penggunaan operator genetika semisal crossover dan mutasi.

\section{REFERENSI}

[1] J. Li, Q. Sun, M. Zhou and X. Dai, "A New Multiple Traveling Salesman Problem and its Genetic Algorithm-based Solution," in 2013 IEEE International Conference on Systems, Man, and Cybernetics, 2013.

[2] W. Liu, S. Li, F. Zhao and A. Zheng, "An Ant Colony Optimization Algorithm for the Multiple Traveling Salesmen Problem," in IEEE, 2009.

[3] Y. Chan and S. F. Baker, "The Multiple Depot, Multiple Traveling Salesmen FacilityLocation Problem: Vehicle Range, Service Frequency, and Heuristic Implementations," Mathematical And Computer Modelling, pp. 1035-1053, 2005.

[4] R. Sivakumar and S. Raja, "Lower and Upper Bounds for a Symmetric Multiple Depot, Multiple Travelling Salesman Problem," Institute of Transportation Studies, University of California at Berkeley, 2006.

[5] S. Sariel and T. Balch, "Real Time Auction Based Allocation of Tasks for Multi-Robot Exploration Problem in Dynamic Environments," in In the 20th National Conference on Artificial Intelligence (AAAI-05) Pittsburgh, Pennsylvania, 2005.

[6] K. Helsgaun, "An Extension of the Lin-Kernighan-Helsgaun TSP Solver for Constrained Traveling Salesman and Vehicle Routing Problems," Department of Computer Science, Roskilde University, DK-4000 Roskilde, Denmark, 2017.

[7] T. Bektas, "The Multiple Traveling Salesman Problem: An Overview of Formulations and Solution Procedures," omega, vol. 34, pp. 209-219, 2006.

[8] J. L. Ryan, T. G. Bailey, J. T. Moore and W. B. Carlton, "Reactive Tabu Search in Unmanned Aerial Reconnaissance Simulation," in IEEE Winter Simulation Conference, 1998.

[9] P. M. Thompson and H. N. Psaraftis, "Cyclic transfer algorithms for mutivehicle routing and scheduling problems," Operations Research, vol. 41, no. 5, pp. 935-946, 1993.

[10] F. Chen, P. Deng, T. Ding and W. Liang, "Research on Ant Colony Optimization Tabu Search and Genetic Fusion Algorithm," in 2nd International Conference on Robotics and Automation Sciences, 2018. 
[11] M. F. Uslu, S. Uslu and F. Bulut, "An adaptive hybrid approach: Combining genetic algorithm and ant colony optimization for integrated process planning and scheduling," Applied Computing and Informatics, pp. 1-7, 2018.

[12] L.-C. Lu and T.-W. Yue, "Mission-oriented ant-team ACO for min-max MTSP," Applied Soft Computing Journal, vol. 76, pp. 436-444, 2019. 